\title{
Plasticity of Plant N Uptake in Two Native Species in Response to Invasive Species
}

\author{
Yi-Heng Hu ${ }^{1}$, Yu-Lu Zhou ${ }^{1,2}$, Jun-Qin Gao ${ }^{1, *}$, Xiao-Ya Zhang ${ }^{1}$, Ming-Hua Song ${ }^{3}$ \\ and Xing-Liang $\mathrm{Xu}^{3}$ \\ 1 School of Ecology and Nature Conservation, Beijing Forestry University, Beijing 100083, China; \\ h.y.h.1992@163.com (Y.-H.H.); zylrainy0318@163.com (Y.-L.Z.); zhangxiaoya5835@163.com (X.-Y.Z.) \\ 2 Guizhou Water Conservation Science and Research Institute, Guiyang 550002, China \\ 3 Key Laboratory of Ecosystem Network Observation and Modeling, Institute of Geographic Sciences and \\ Natural Resources Research, Chinese Academy of Sciences, Beijing 100101, China; \\ songmh@igsnrr.ac.cn (M.-H.S.); xuxl@igsnrr.ac.cn (X.-L.X.) \\ * Correspondence: gaojq@bjfu.edu.cn
}

Received: 28 September 2019; Accepted: 23 November 2019; Published: 27 November 2019

\begin{abstract}
Survival competition caused by limiting nutrients is often strong between invasive and native plant species. The effects of plant invasion on nutrient uptake in plant growth remain largely unclear. Clarifying how invasive plants affect $\mathrm{N}$ uptake by natives will provide a better understanding on mechanisms responsible for plant invasion. $\mathrm{A}^{15} \mathrm{~N}$-labeling experiment was conducted using two common invasive species (Alternanthera philoxeroides (Mart.) Griseb. and Wedelia trilobata (L.) Hitchc.) and their native congeners (A. sessilis (L.) DC. and W. chinensis (Osbeck.) Merr.) to examine their growth and uptake of $\mathrm{NH}_{4}{ }^{+}, \mathrm{NO}_{3}{ }^{-}$, and glycine when grown in monocultures and mixed cultures. All plants were grown in a greenhouse for 70 days for labelling and biomass measurements. The main factor affecting $\mathrm{N}$ uptake by the four species was the form of $\mathrm{N}$, rather than species identity. In all of the species, the most $\mathrm{N}$ was taken up in the form of $\mathrm{NH}_{4}{ }^{+}$, followed by $\mathrm{NO}_{3}{ }^{-}$and glycine. The two invasive species grew faster, with stable $\mathrm{N}$-uptake patterns despite more moderate uptake rates of $\mathrm{N}$ than the native species. Native species were strongly affected by the invasive species. The presence of invasive species caused the $\mathrm{N}$-uptake rates of the natives to be reduced, with altered $\mathrm{N}$-uptake patterns, but did not substantially alter their growth rates. Native species reduced their $\mathrm{N}$-uptake rates but increased $\mathrm{N}$-use efficiency through altering $\mathrm{N}$-uptake patterns in the presence of invasive plants. Such a flexible $\mathrm{N}$-uptake pattern could be an important survival strategy for native plants in competition with invaders.
\end{abstract}

Keywords: ${ }^{15} \mathrm{~N}$ labelling; N-uptake pattern; invasive species; native species; resource competition; survival strategy

\section{Introduction}

Invasion by exotic plants can have severe impacts on the species composition and structure of communities [1,2], and on the growth and development of native flora [1]. It has caused a large decline in species richness and is still a big threat to many ecosystems including tropical and subtropical forests [3]. The effects of plant invasion on native plants are partly due to competition for limited resources between natives and non-natives [4,5], especially for the limited nutrients that are essential for plants to grow [6]. The effects of plant invasions on native plant growth-for example, non-native shrub Spartium junceum L. promotes aboveground biomass of native vegetation, whereas invasive grass Phalaris arundinacea $\mathrm{L}$. reduces the biomass of native Carex hystericina Muhl.—are well documented $[7,8]$. 
However, it remains largely unknown how plant invasion affects nutrient uptake by native species and how it relates to their plant growth.

As a major component of nucleic acids and proteins, nitrogen relates to plant growth, development, and reproduction [9]. However, N-limitation is a major factor limiting plant growth in most terrestrial ecosystems [10]. Therefore, $\mathrm{N}$ uptake by plants is crucial for their growth, especially when species are growing together. With the exception of some plant species that use atmospheric $\mathrm{N}_{2}$ via symbiotic rhizobia, most plants take up mineral $\mathrm{N}$ in the form of ammonium $\left(\mathrm{NH}_{4}\right)$ and nitrate $\left(\mathrm{NO}_{3}\right)$, and organic $\mathrm{N}$ in the form of amino acids from the soil solution via their roots or associated fungi [11-13]. This process differs between plant species and can be modified by neighbouring species [14-16]. A neighbouring plant can influence the $\mathrm{N}$-uptake preference of a target species (such as from preference for $\mathrm{NO}_{3}$ to preference for $\mathrm{NH}_{4}$, or from preference for $\mathrm{NO}_{3}$ to no preference) and enhance or reduce their $\mathrm{N}$ uptake rate $[15,17-19]$. The alterations in $\mathrm{N}$ uptake by plants can subsequently alter their growth-related metabolism and traits, such as photosynthetic rate, leaf area and biomass, but the performance varies among species [20-23]. This indicates that $\mathrm{N}$ uptake by native species may differ depending on the presence or absence of invasive species, and the potential differences may be the reason for their growth changes. Thus, assessing the effects of plant invasions on the $\mathrm{N}$-uptake patterns and growth performances of native and invasive species could offer great insights into the underlying mechanisms of plant invasions. However, to date, few studies have investigated the effects of plant invasions on $\mathrm{N}$-uptake patterns.

To explore how invasive plants affect the uptake of organic and mineral $\mathrm{N}$ by natives, we conducted a ${ }^{15} \mathrm{~N}$-labeling experiment in greenhouse conditions with two typical invasive species, Alternanthera philoxeroides (Mart.) Griseb. (Amaranthaceae) and Wedelia trilobata (L.) Hitchc. (Asteraceae), and two native congeners, A. sessilis (L.) DC. and W. chinensis (Osbeck.) Merr., as the target plant species that commonly co-occur in the wild in southern China. We examined the uptake of $\mathrm{NH}_{4}{ }^{+}, \mathrm{NO}_{3}{ }^{-}$, and glycine by these species in both monoculture and mixed culture environments. We aimed to test the hypotheses: (1) The native species can change their $\mathrm{N}$-uptake patterns in response to the presence of invasive species; (2) The extent of this change depends on species identity.

\section{Materials and Methods}

\subsection{Target Species}

In this study, we selected two widespread invasive species, Alternanthera philoxeroides and Wedelia trilobata, and their native congeners, A. sessilis and W. chinensis (Table 1). Alternanthera philoxeroides is native to South America, and W. trilobata is native to North and South America; both species are known to be highly invasive. Alternanthera philoxeroides has invaded all continents except Africa and Europe; it grows in a wide range of habitats, from dry terrestrial to aquatic ecosystems [24]. Wedelia trilobata is widely distributed in tropical areas and is listed as one of the worst invasive alien species [25]. Both invasive species are potential threats to tropical and subtropical forests because the warm and wet climate in these ecosystems is suitable for the growth of the two species. Alternanthera sessilis and W. chinensis are native to China and are not invasive. All four species are perennial herbs and clonal plants which reproduce mainly by their creeping stems.

Alternanthera philoxeroides and A. sessilis were collected in May 2011 and in Zhejiang Province, and W. trilobata and W. chinensis were collected in July 2009 and in Guangdong Province, China. Five individual ramets of each species were collected from individuals at least $10 \mathrm{~m}$ apart, in each of the two populations of each species. Using vegetative propagation, we selected plants of similar size and cultivated them in a greenhouse at the Forest Science Company of Beijing Forestry University. 
Table 1. Native and invasive species selected to assess the effects of plant invasion on $\mathrm{N}$ uptake of plant species in the ${ }^{15} \mathrm{~N}$-labeling experiment.

\begin{tabular}{ccccc}
\hline Family & Species & Status & Native Range & Habitat \\
\hline \multirow{2}{*}{ Amaranthaceae } & Alternanthera philoxeroides & Invasive & South America \\
Alternanthera sessilis & Native & Asia, Africa \\
Asteraceae & Wedelia trilobata & Invasive & $\begin{array}{c}\text { North and } \\
\text { South America }\end{array}$ & $\begin{array}{c}\text { Canals, wetlands, nearby fields } \\
\text { Moist habitats } \\
\text { canals, roadsides }\end{array}$ \\
& Wedelia chinensis & Native & Asia & $\begin{array}{c}\text { Moist grasslands, edges of } \\
\text { canals, roadsides, crop fields }\end{array}$ \\
\hline
\end{tabular}

\subsection{Experimental Design}

In May 2014, 100 microcosms were constructed using four individual ramets per microcosm (Figure 1). For the monocultures, each of the four species was represented by 12 replicates, making a total of 48 microcosms ( 4 species $\times 12$ replicates). For the mixed cultures, one invasive species and one native species (two species, and two ramets of each species) was selected per treatment, also producing 48 microcosms ( 4 mixtures $\times 12$ replicates). Four microcosms with one ramet of each species were used for the control culture to measure the natural abundance of $\mathrm{N}$ for the calculation of atom $\%$ excess ${ }^{15} \mathrm{~N}$.

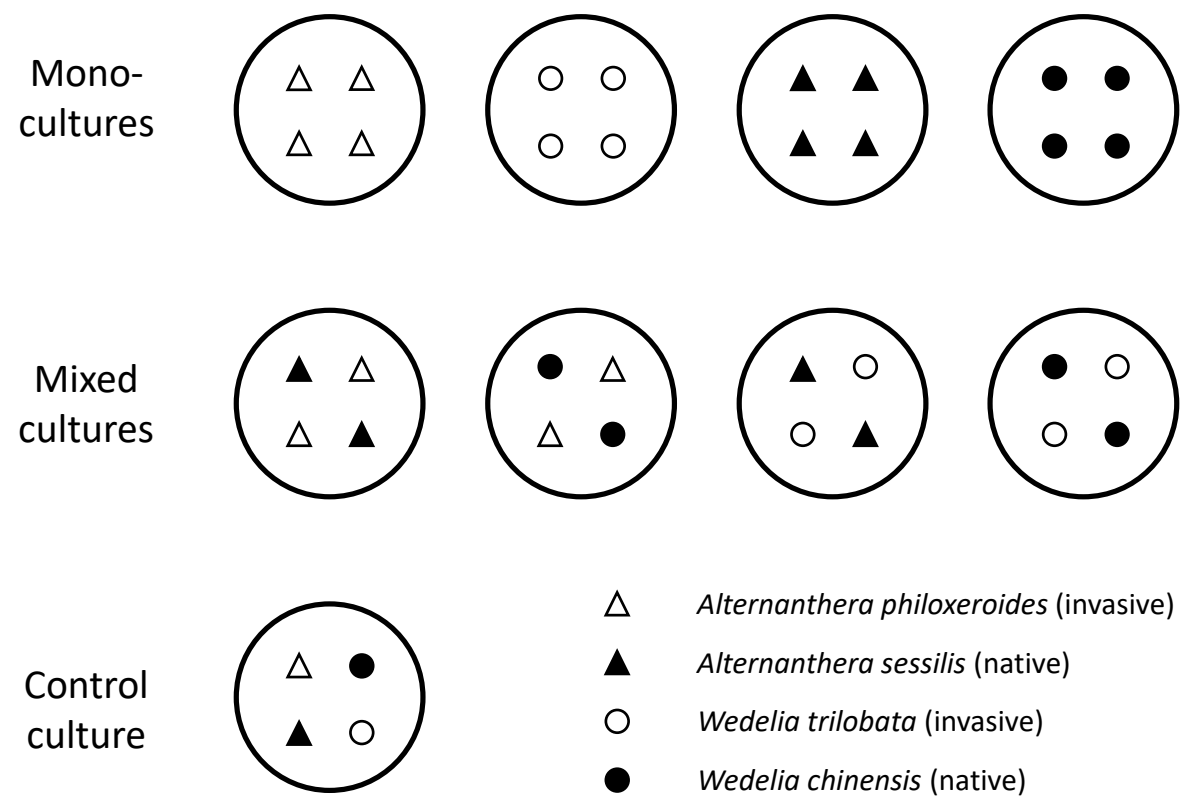

Figure 1. Schematic illustration of culture treatments (monocultures, mixed cultures, and control) including two invasive species (Alternanthera philoxeroides (Mart.) Griseb. and Wedelia trilobata (L.) Hitchc.) and two native species (A. sessilis (L.) DC. and W. chinensis (Osbeck.) Merr) used in this experiment.

The experiment was carried out using a pot $(50 \mathrm{~cm}$ and $30 \mathrm{~cm}$, height and inner diameter respectively) setup. The containers were filled with a 1:1 mixture of washed river sand and peat moss (Pindstrup Substrate, Pindstrup Mosebrug AS, Denmark). The substrates were common in cultivated experiments and constructed a moderate $\mathrm{N}$ environment. All plants were grown in the same greenhouse conditions: air temperature ranged from $27^{\circ} \mathrm{C}$ to $36^{\circ} \mathrm{C}$, and relative humidity ranged from $40 \%$ to $60 \%$. The conditions were maintained during both the cultivation and experimental periods. The plants were watered daily with tap water and no extra minerals were added.

After growing for 70 days, on 2 July 2014, 12 replicates in each treatment were randomly subjected to the addition of $\mathrm{NH}_{4}{ }^{-15} \mathrm{~N}(99.2 \%), \mathrm{NO}_{3}{ }^{-15} \mathrm{~N}(99.2 \%)$, or glycine- ${ }^{15} \mathrm{~N}(98.7 \%)$. There were four replicate microcosms for each $\mathrm{N}$ chemical form treatment. The labelling solutions contained $78 \mathrm{mg} \mathrm{N} \mathrm{L}^{-1}$, each providing the same amount $\left(26 \mathrm{mg} \mathrm{N} \mathrm{L}^{-1}\right)$ of $\mathrm{NH}_{4}-\mathrm{N}, \mathrm{NO}_{3}-\mathrm{N}$, and glycine- $\mathrm{N}$; in each solution, only 
one $\mathrm{N}$ chemical form was labelled with ${ }^{15} \mathrm{~N}$. The $\mathrm{N}$ solution $(4 \mathrm{~mL})$ was sprayed uniformly on the soil. The amount of $\mathrm{N}$ supplied was equal to $3.9 \mu \mathrm{g} \mathrm{N} \mathrm{g}{ }^{-1}$ dry weight (d.w.) soil, or $\sim 10 \%$ of the average mineral $\mathrm{N}$ concentration in this soil type.

\subsection{Sampling and Isotope Analysis}

Plant and soil samples were collected $2 \mathrm{~h}$ after ${ }^{15} \mathrm{~N}$ labelling, considering the rapid turnover of amino acids in soil [26]. Plant shoots and roots were harvested, rinsed with water, soaked in $0.5 \mathrm{mM}$ $\mathrm{CaCl}_{2}$ solution for $30 \mathrm{~min}$, and rinsed with distilled water to remove the ${ }^{15} \mathrm{~N}$ adsorbed on the surface of the roots. Shoots and roots of the specimens were carefully separated. Soil was transferred to the laboratory within $30 \mathrm{~min}$ and processed immediately.

Shoots and roots were dried at $70{ }^{\circ} \mathrm{C}$ for $48 \mathrm{~h}$, weighed to measure the biomass, and then ground into a fine powder using a ball mill (MM400, Retsch, Haan, Germany). A subsample of 2 mg of this powder was used to measure total $\mathrm{N}$, and atom $\%{ }^{15} \mathrm{~N}$ was determined using an isotope ratio mass spectrometer with a Flash EA1112 and Conflo III interface (MAT 253, Finnigan MAT, Bremen, Germany).

The fresh soil was sieved to measure moisture content, mineral $\mathrm{N}\left(\mathrm{NH}_{4}{ }^{+}\right.$and $\left.\mathrm{NO}_{3}{ }^{-}\right)$, and glycine. The soil moisture content was measured using the oven drying method (dried at $80{ }^{\circ} \mathrm{C}$ ). Soil samples were extracted with $0.05 \mathrm{~mol} \mathrm{~L}^{-1} \mathrm{~K}_{2} \mathrm{SO}_{4}$ and shaken. The filtered extracts were measured for $\mathrm{NH}_{4}{ }^{+}$and $\mathrm{NO}_{3}{ }^{-}$concentrations using an auto-analyser (AA3, SEAL, Norderstedt, Germany). Soil glycine concentrations were measured in the extracts by high-performance liquid chromatography (Ultimate3000, Thermo fisher, Waltham, MA USA; API 3200 Q TRAP, Agilent, Lexington, MA USA).

\subsection{Data Analysis}

Atom $\%$ excess ${ }^{15} \mathrm{~N}$ (APE) was calculated as the atom $\%{ }^{15} \mathrm{~N}$ difference between plants from the ${ }^{15} \mathrm{~N}$-added plots (atom $\%{ }^{15} \mathrm{~N}_{\text {added }}$ ) and plants from the control plots (atom $\%{ }^{15} \mathrm{~N}_{\text {control }}$ ). For each species, the ${ }^{15} \mathrm{~N}$ uptake rate $\left(\mu \mathrm{g}{ }^{15} \mathrm{~N} \mathrm{~g}^{-1} \mathrm{~d}\right.$.w. root $\left.\mathrm{h}^{-1}\right)$ was calculated by multiplying the $\mathrm{N}$ content $\left(\mu \mathrm{mol} \mathrm{N} \mathrm{g}^{-1}\right)$, APE $(\%)$, relative molecular mass of ${ }^{15} \mathrm{~N}\left(\mathrm{~g} \mathrm{~mol}^{-1}\right)$, and total plant biomass $(\mathrm{g})$, and then dividing by root mass $(\mathrm{g})$ and time $(\mathrm{h})$. Actual $\mathrm{N}$ uptake from soil by plants $\left(\mu \mathrm{g} \mathrm{N} \mathrm{g}{ }^{-1} \mathrm{~d} . \mathrm{w}\right.$. root $\left.\mathrm{h}^{-1}\right)$ was calculated by multiplying the ${ }^{15} \mathrm{~N}$-uptake rate by the corresponding $\mathrm{N}$ pool (i.e., $\mathrm{NH}_{4}{ }^{+}, \mathrm{NO}_{3}{ }^{-}$, or glycine) in soil, divided by the total amount of ${ }^{15} \mathrm{~N}$ added $[27,28]$.

We used one-way analysis of variance (ANOVA) followed by Duncan tests to examine the differences in total biomass among the four target species. Two-way ANOVA was used to test the effects of species identity, $\mathrm{N}$ form $\left(\mathrm{NH}_{4}{ }^{+}, \mathrm{NO}_{3}{ }^{-}\right.$, and glycine), and their interactions on the $\mathrm{N}$-uptake rate, followed by a Duncan test to compare individual means. One-way ANOVA was used to examine the differences in soil mineral $\mathrm{N}$ contents between monocultures and mixed cultures. The analyses were conducted using SPSS 18.0 (SPSS Inc., Chicago, IL, USA). Effects were considered to be significant at $p<0.05$.

\section{Results}

The total (above + belowground) biomass of the invasive plants was much higher than that of the congeneric native species in both monocultures and mixed cultures (Figure 2). Both above and belowground mass showed the same trends as the total biomass [29]. Among culture treatments, the biomass of invasive $A$. philoxeroides in the mixtures was significantly higher than that in the monocultures. The biomass of native $A$. sessilis in the mixture with $W$. trilobata was more than twice that grown in monoculture. There was no significant difference in the biomass of $W$. trilobata or W. chinensis between monoculture and mixed culture treatments. In general, the biomass was not lower in the mixed cultures than in the monocultures for either the invasive species or the natives. 

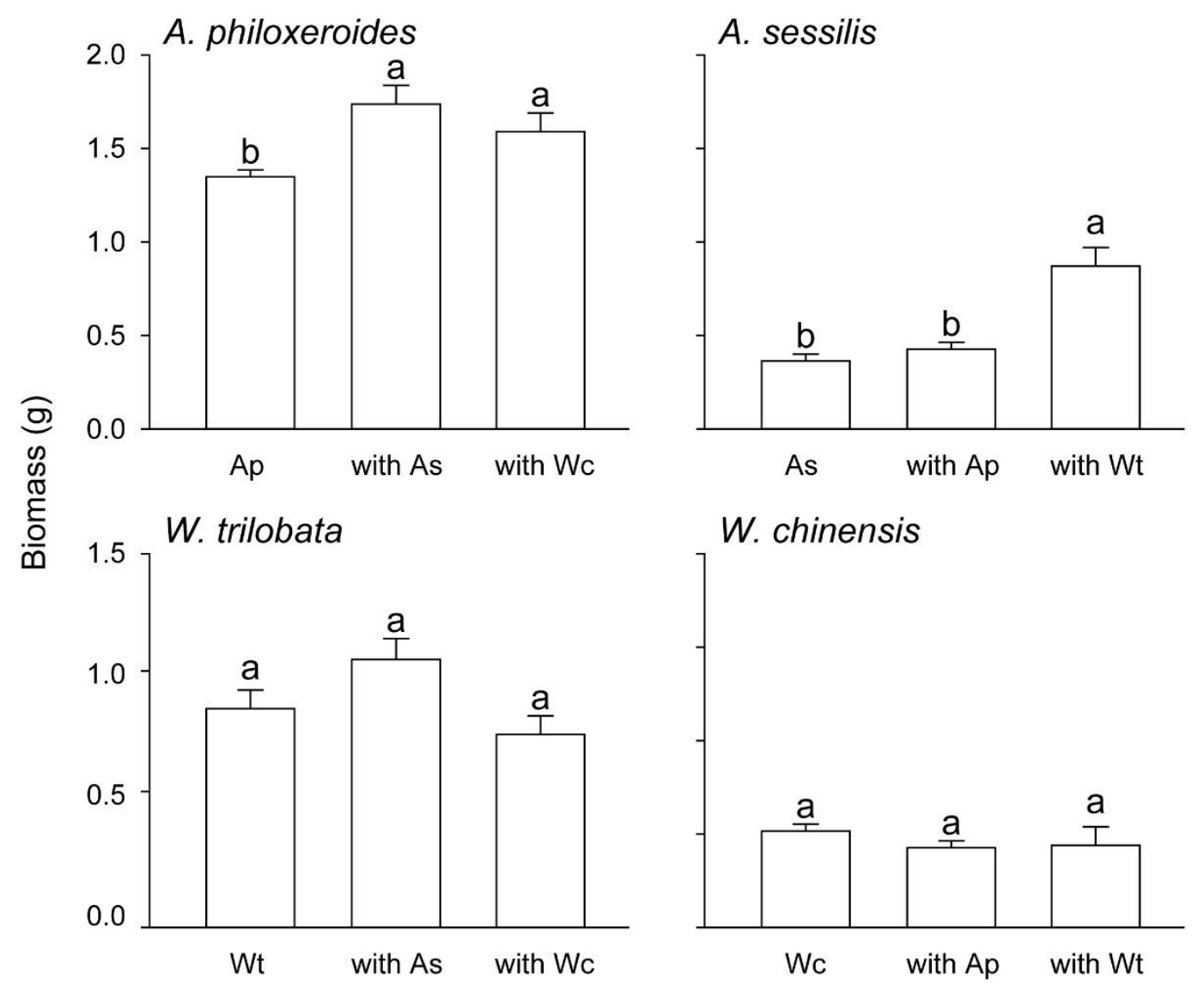

W. chinensis

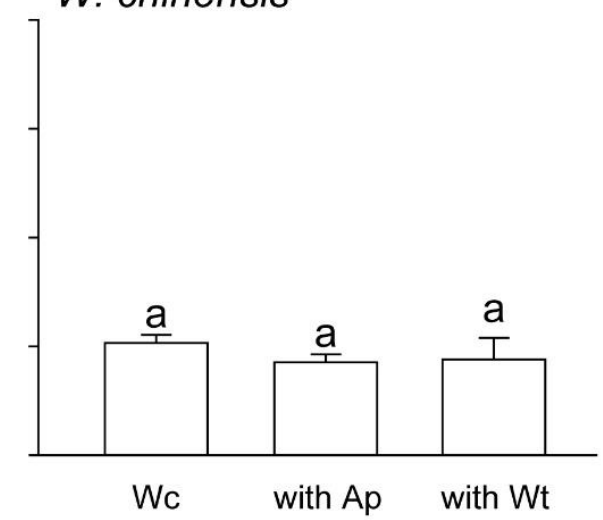

Figure 2. Total (above + belowground) biomass of the four plant species: Alternanthera philoxeroides (Ap) (invasive), A. sessilis (As) (native), Wedelia trilobata (Wt) (invasive), and W. chinensis (Wc) (native). The plants were grown in monoculture, or mixed with individuals of different origin, as indicated. Bars and error bars indicate means \pm standard errors (SE) $(n=12)$. Bars with the same lowercase letter are not significantly different at $p<0.05$.

In monocultures, the two invasive species (A. philoxeroides and W. trilobata) had similar N-uptake rates, which were lower than that of native $A$. sessilis but higher than that of native $W$. chinensis (Figure 3). Mixed culture did not alter the content of mineral $\mathrm{N}$ in soil or the relative magnitude of $\mathrm{N}$ uptake by the four species (Table 2, Figure 3). The $\mathrm{N}$-uptake rate of invasive A. philoxeroides did not differ significantly between monocultures and mixed cultures. However, the $\mathrm{N}$-uptake rates of the two native species (A. sessilis and W. chinensis) decreased when in competition with A. philoxeroides. The $\mathrm{N}$-uptake rate of invasive $W$. trilobata was lower when in competition with the other species, and in turn also greatly reduced the N-uptake rates of native A. sessilis. Overall, the native species had lower $\mathrm{N}$-uptake rates in three of the four mixtures with the invasive species than in monocultures.

The identity of the neighbouring species had no significant effect on the N-uptake rates by plants, except in the case of $W$. trilobata, whereas $\mathrm{N}$-uptake rates were significantly different across all $\mathrm{N}$ forms for both native and invasive species (Table 3). There was no interaction between species identity and $\mathrm{N}$ form in their effects on plant $\mathrm{N}$ uptake. These results emphasize the importance of $\mathrm{N}$ forms for $\mathrm{N}$ uptake by plants. 

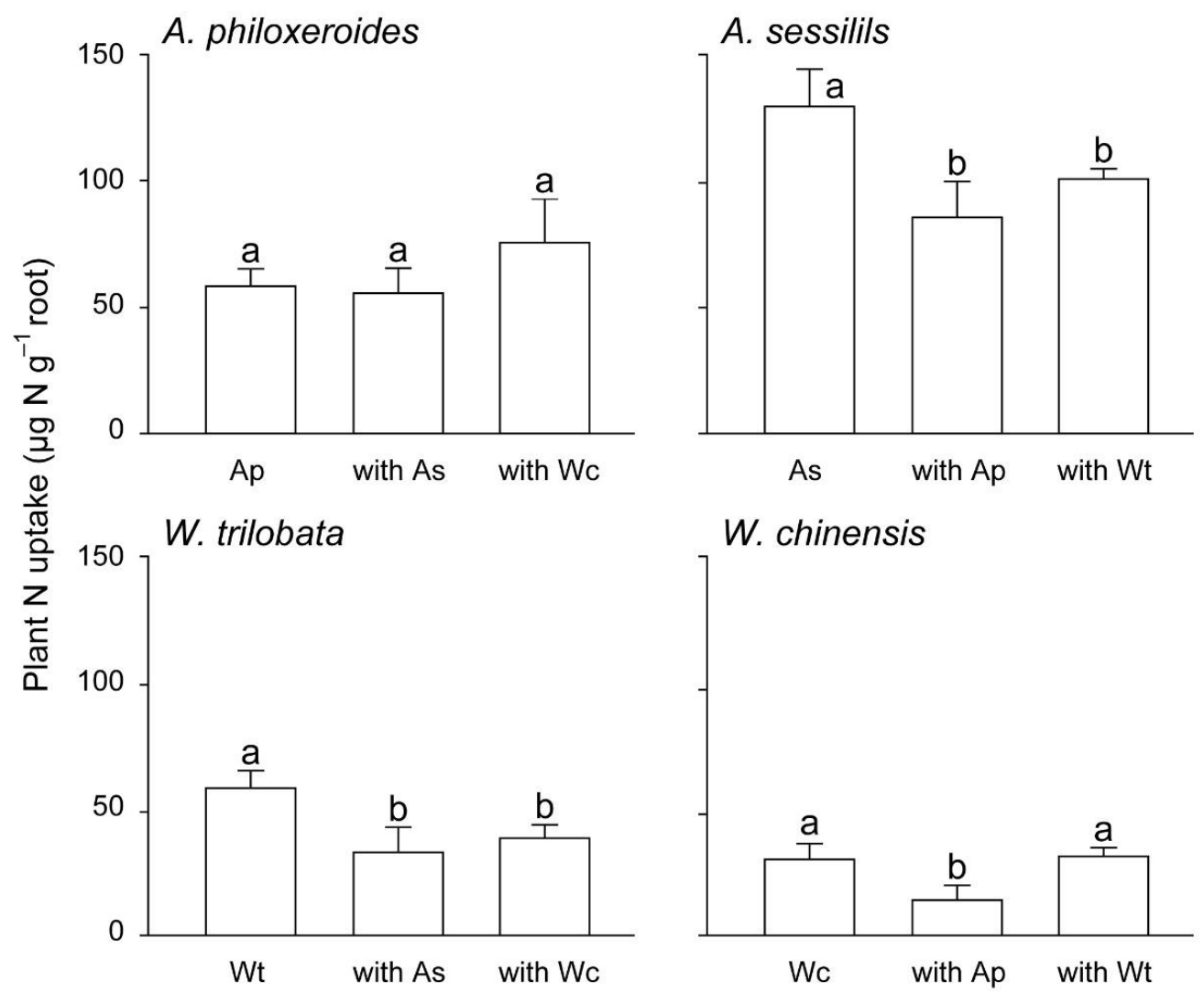

Figure 3. Effects of culture treatments on $\mathrm{N}$ uptake by plants: Alternanthera philoxeroides (Ap) (invasive), A. sessilis (As) (native), Wedelia trilobata (Wt) (invasive), and W. chinensis (Wc) (native). The plants were grown in monoculture, or mixed with individuals of different origin. Bars and error bars indicate means \pm SE $(n=4)$. Bars with the same lowercase letter are not significantly different at $p<0.05$.

Table 2. Effects of culture treatments on the soil mineral $\mathrm{N}$ contents of invasive species Alternanthera philoxeroides and Wedelia trilobata, and native species $A$. sessilis and W. chinensis. The plants were grown in monoculture, or mixed with individuals of different origin.

\begin{tabular}{ccccc}
\hline \multirow{2}{*}{ Species } & \multicolumn{2}{c}{$\mathbf{N H}_{4}{ }^{+}$} & \multicolumn{2}{c}{$\mathbf{N O}_{3}{ }^{-}$} \\
\cline { 2 - 5 } & $\boldsymbol{F}_{3,36}$ & $\boldsymbol{p}$ & $\boldsymbol{F}$ & $\boldsymbol{p}$ \\
\hline A. philoxeroides & 1.44 & 0.249 & 1.18 & 0.330 \\
W. trilobata & 0.60 & 0.617 & 0.96 & 0.424 \\
A. sessilis & 1.43 & 0.249 & 0.83 & 0.485 \\
W. chinensis & 0.68 & 0.570 & 1.15 & 0.341 \\
\hline
\end{tabular}

Table 3. ANOVA results for the effects of species identity, $\mathrm{N}$ form, and their interactions on $\mathrm{N}$ uptake rate by four species: Alternanthera philoxeroides (invasive), Wedelia trilobata (invasive), A. sessilis (native), and $W$. chinensis (native). The plants were grown in monoculture, or mixed with individuals of different origin.

\begin{tabular}{ccccccc}
\hline \multirow{2}{*}{ Species } & \multicolumn{2}{c}{ Species Identity } & \multicolumn{2}{c}{ N Form } & \multicolumn{2}{c}{ Interaction } \\
\cline { 2 - 7 } & $\mathbf{F}_{\mathbf{2}, \mathbf{1 8}}$ & $\boldsymbol{p}$ & $\mathbf{F}$ & $\boldsymbol{p}$ & $\mathbf{F}$ & $\boldsymbol{p}$ \\
\hline A. philoxeroides & 2.0 & 0.164 & $\mathbf{2 7 . 6}$ & $<\mathbf{0 . 0 0 1}$ & 0.7 & 0.608 \\
W. trilobata & $\mathbf{4 . 4}$ & $\mathbf{0 . 0 2 8}$ & $\mathbf{4 9 . 0}$ & $<\mathbf{0 . 0 0 1}$ & 1.8 & 0.167 \\
A. sessilis & 1.1 & 0.372 & $\mathbf{7 4 . 5}$ & $<\mathbf{0 . 0 0 1}$ & 0.6 & 0.656 \\
W. chinensis & 1.5 & 0.248 & $\mathbf{1 5 . 0}$ & $<\mathbf{0 . 0 0 1}$ & 0.8 & 0.519 \\
\hline
\end{tabular}

Values in bold indicate significant differences at $p<0.05$. 
In monocultures, all four plant species showed the same $\mathrm{N}$-uptake patterns for the three $\mathrm{N}$ forms, with the highest preference being for $\mathrm{NH}_{4}{ }^{+}$, and a lower preference for glycine than for $\mathrm{NO}_{3}{ }^{-}$(Figure 4). The competition with invasive $A$. philoxeroides increased the uptake rate of glycine but reduced the uptake rate of $\mathrm{NO}_{3}{ }^{-}$in $A$. sessilis, and greatly increased the uptake rate of $\mathrm{NO}_{3}{ }^{-}$, but significantly reduced the uptake rate of $\mathrm{NH}_{4}{ }^{+}$in $W$. chinensis. The competition with $W$. trilobata significantly reduced the glycine uptake rates of the two native species (Figure 4). Overall, the contributions of the three $\mathrm{N}$ forms in the invasive species (A. philoxeroides and $W$. trilobata) were similar in the absence and presence of native plants, whereas the two native species (A. sessilis and $W$. chinensis) altered their N-uptake patterns in the presence of the exotic neighbours.

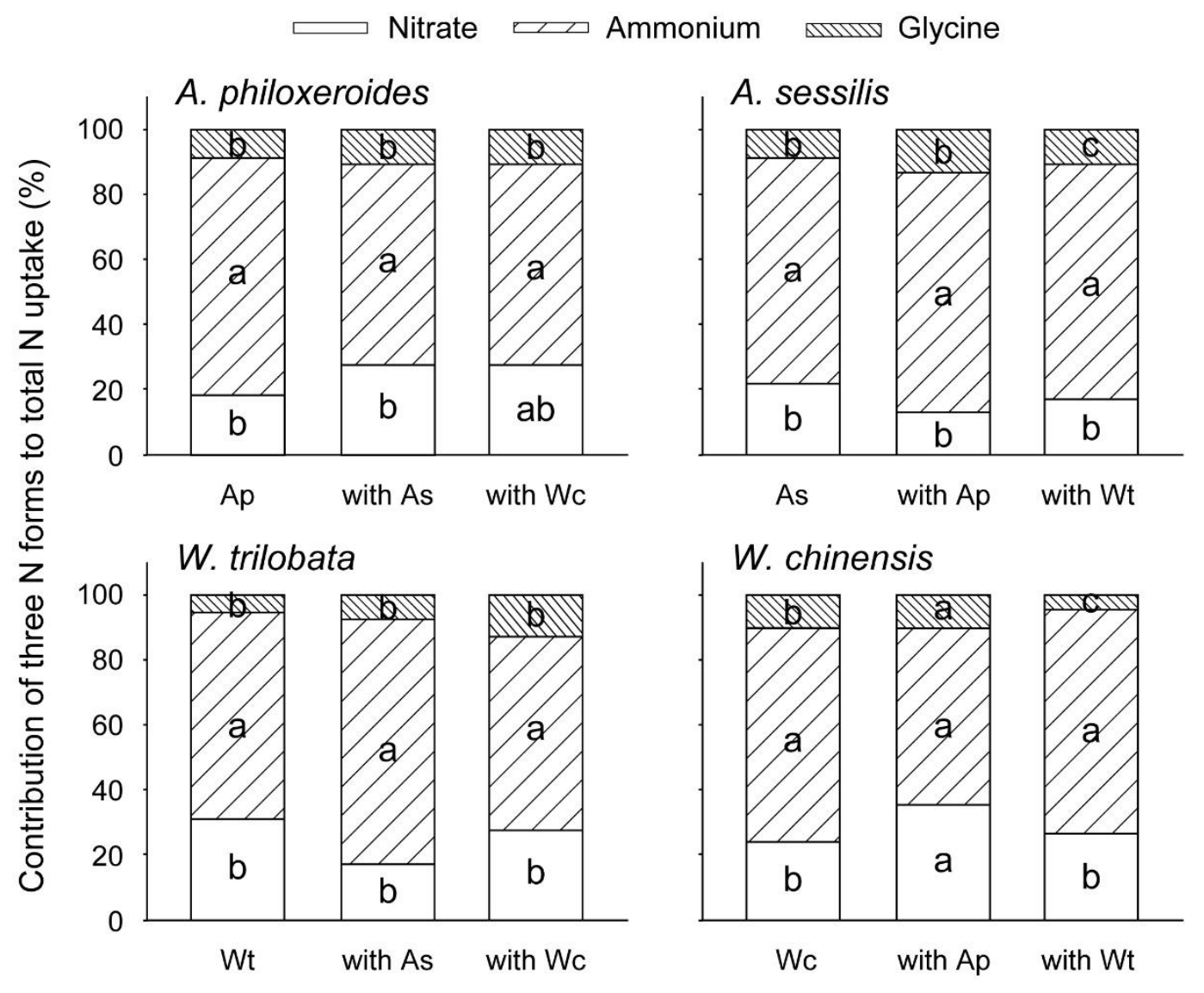

Figure 4. Patterns of $\mathrm{N}$ uptake for invasive species, Alternanthera philoxeroides (Ap) and Wedelia trilobata $(\mathrm{Wt})$, and native species, $A$. sessilis (As) and W. chinensis (Wc). The plants were in monoculture, or mixed with individuals of different origin. Bars with the same lowercase letter are not significantly different at $p<0.05$.

\section{Discussion}

Using a ${ }^{15} \mathrm{~N}$-labeling experiment in a greenhouse, we compared the biomass and $\mathrm{N}$ uptake between invasive (A. philoxeroides and $W$. trilobata) and native (A. sessilis and $W$. chinensis) plants when grown as monocultures, and the differences in growth and $\mathrm{N}$ uptake of these species between monocultures and mixed cultures. The results showed that native plants altered their N-uptake patterns, reduced their N-uptake rates, but maintained their biomass in the presence of invasive species. These results confirm our first hypothesis and highlight the important role of $\mathrm{N}$ uptake to growth in plant invasion. Determining the $\mathrm{N}$ uptake and growth performance of these plants provides a better understanding of the differences between invasive and native species and the impacts of plant invasion on natives, both externally (in terms of biomass) and internally (in terms of $\mathrm{N}$ uptake). 
The higher biomass of the invasive species in both monocultures and mixed cultures indicated that the invasive species grew faster and with stronger competitive ability than their native congeners that we studied. This result is similar to previous observations in the wild $[30,31]$. The differences in growth rates between native and non-native plants may be a result of different physiological, ecological, and functional characteristics [32]. Most invasive species have fast growth rates and a large biomass $[30,31,33,34]$, which may enable the invaders to dominate in their competition with native species and to take up more $\mathrm{N}$ via their larger roots [29].

The $\mathrm{N}$-uptake rates of the invasive species were intermediate compared with those of the native plants. It is noteworthy that the order of $\mathrm{N}$-uptake rates by four species were inconsistent with their order of total biomass. This lack of association between $\mathrm{N}$-uptake rate and biomass implies that the two invasive species had higher $\mathrm{N}$-use efficiency than the native species, as is common in other invasive plants $[34,35]$. Higher $\mathrm{N}$-use efficiency rather than faster $\mathrm{N}$-uptake rate appears to be a strategy that enables these invasive species to be more competitive than the natives.

Numerous studies have shown that plant $\mathrm{N}$ uptake is related to species identity, to $\mathrm{N}$ form, and to $\mathrm{N}$ content $[14,16,36,37]$. In the current study, we found that $\mathrm{N}$ form was the major factor affecting plant $\mathrm{N}$ uptake, while species identity had a more variable influence across the four observed species. This finding is similar to the results reported by Miller et al. for an alpine dry meadow, where $\mathrm{N}$ form significantly affected ${ }^{15} \mathrm{~N}$ uptake by all plants whereas neighbour identity only affected ${ }^{15} \mathrm{~N}$ uptake by one out of three species [15]. All four species preferentially took up $\mathrm{NH}_{4}{ }^{+}$, with intermediate uptake of $\mathrm{NO}_{3}{ }^{-}$, and a lower uptake of glycine. The $\mathrm{N}$-uptake rates from different $\mathrm{N}$ forms depend on differences in the availability and content of the $\mathrm{N}$ forms in the soil [36], energy consumption of $\mathrm{N}$ uptake, and pathways of $\mathrm{N}$ assimilation used by plants [38]. The order of $\mathrm{N}$-uptake preference of these species matches the order of the amounts of each $\mathrm{N}$ source in the soil $\left(\mathrm{NH}_{4}{ }^{+}\right.$and $\mathrm{NO}_{3}{ }^{-}>$glycine, in this experiment) and the amount of energy required for $\mathrm{N}$ assimilation $\left(\mathrm{NO}_{3}{ }^{-}>\mathrm{NH}_{4}{ }^{+}\right.$, [39]). Overall, both native and non-native plants had the same $\mathrm{N}$-uptake pattern, especially in monocultures, which may relate to the same functional groups of all species in our study.

Hewins and Hyatt concluded that flexible $\mathrm{N}$ uptake mechanisms of invasive Alliaria petiolata under various $\mathrm{N}$ environments might assist its invasion in forests of eastern North America [40]. In our study, under the same environment, invasive $W$. trilobata had lower $\mathrm{N}$ uptake when grown in mixed cultures with the natives, whereas invasive A. philoxeroides had a similar $\mathrm{N}$ uptake under both conditions compared with $\mathrm{N}$ uptake in monocultures. However, the two invasive species showed the same $\mathrm{N}$-uptake pattern between monocultures and mixed cultures. The more stable $\mathrm{N}$-uptake pattern of the invasive species may be due to their dominant position in competition with the natives. This suggestion is supported by our finding that the invasive plants were able to maintain their rapid growth in a co-occurring environment.

In contrast, native species were strongly affected by the invasives, i.e., natives showed altered patterns of $\mathrm{N}$-uptake forms and reductions in $\mathrm{N}$-uptake rates. The decrease of $\mathrm{N}$ uptake of the natives provides evidence of the strong $\mathrm{N}$ competition between the native and invasive plants, and the competitive disadvantage of native species. Moreover, the changes in $\mathrm{N}$-uptake patterns by native plants confirmed our first hypothesis that the $\mathrm{N}$-uptake patterns of the natives can change in response to the presence of invasive species. Although the altered N-uptake patterns of the two natives differed among the four mixtures with the invasives, these differences nonetheless indicate the importance of species identity.

The alterations in N-uptake patterns by native plants may be a result of the absorption of specific, preferred $\mathrm{N}$ forms by the invasive species; of the production of secondary compounds by the invasive species that disrupt other species [40,41]; or of plant-microbe-soil interactions that affect the availability of $\mathrm{N}$ in the soil [41-43]. In our study, the soil mineral $\mathrm{N}$ did not differ significantly between the microcosms of native and invasive plants in both monocultures and mixed cultures. More importantly, the biomass of the natives was not lower in the presence of invasive plants. These lines of evidence suggest that the changes in $\mathrm{N}$ uptake by native plants are not necessarily driven by the invasive species, 
or affected by altering the availability of $\mathrm{N}$ in the soil. Rather, the shifts in $\mathrm{N}$-uptake patterns may represent an adaptive strategy of the natives. Some plants show diverse N-uptake strategies between isolated culture and competitive environments to facilitate their coexistence [44-46]. Here, we found similar variation in the $\mathrm{N}$-uptake patterns of native species in monocultures and in competition with invasive plants, as expected. Therefore, flexibility in $\mathrm{N}$ uptake could represent a strategy of the native plants to survive under exotic plant invasion. Although the two native species had lower N-uptake rates, they showed equal or even better growth rates and higher $\mathrm{N}$ use efficiencies in the presence of invasive species.

Although the glycine used in our study was only ${ }^{15} \mathrm{~N}$-labeled (rather than ${ }^{13} \mathrm{C}$ - and ${ }^{15} \mathrm{~N}$-labeled), given its low concentration in soil and low uptake rate by plants, this is not expected to have affected the $\mathrm{N}$ uptake exhibited by the plants in our study. Invasive species contribute greatly to species and habit loss worldwide. Conservation and monitoring strategies rely heavily on a strong understanding of the factors that mediate interactions between natives and invasives. Long-term and in-situ experiments are encouraged to further test whether such flexible $\mathrm{N}$ uptake could help native plants survive over a longer period. For example, if some tree species have flexible $\mathrm{N}$ uptake, they may have a higher chance of survival because tree seedlings usually grow slower than a large number of invasive species which rely more on stolon reproduction.

\section{Conclusions}

Our findings suggest a possible survival strategy of native plants in response to exotic plant invasion. The invasive plants had a larger biomass and more stable $\mathrm{N}$ uptake than the natives, indicating their competitive advantage. The native species were strongly affected by the $\mathrm{N}$ competition with the invasives so that the $\mathrm{N}$-uptake rate of the natives declined significantly. However, native plants had equal or even larger biomass in mixed cultures with the invasives than in monocultures. This growth performance may be due to the alterations in N-uptake patterns of the natives. Overall, our study reveals a clear plasticity of $\mathrm{N}$ uptake by native plants and improves our understanding of the role of nutrient uptake in survival competition between invasive and native species.

Author Contributions: Conceptualization and methodology, J.-Q.G., M.-H.S. and X.-L.X.; software, Y.-L.Z. and J.-Q.G.; formal analysis, Y.-H.H., Y.-L.Z. and J.-Q.G.; investigation, Y.-L.Z.; writing-original draft preparation, Y.-H.H.; writing-review and editing, Y.-H.H., J.-Q.G., X.-Y.Z., M.-H.S. and X.-L.X.; funding acquisition, J.-Q.G.

Funding: This research was funded by the National Natural Science Foundation of China (41571084) and the Fundamental Research Funds for the Central Universities (2015ZCQ-BH-01).

Acknowledgments: We thank Ling-Yun Li for assistance with the experiment, Yu-Xi Liu for help with drawing, and Editage for English language editing. We also thank Yakov Kuzyakov, Fei-Hai Yu, Yong-Lin Zhong, and Chen Wang for their constructive advice and suggestions about our study or for comments on the original manuscript.

Conflicts of Interest: The authors declare no conflict of interest.

\section{References}

1. Biswas, S.R.; Biswas, P.L.; Limon, S.H.; Yan, E.; Xu, M.; Khan, M.S.I. Plant invasion in mangrove forests worldwide. For. Ecol. Manag. 2018, 429, 480-492. [CrossRef]

2. Flory, S.L.; Clay, K. Non-native grass invasion alters native plant composition in experimental communities. Biol. Invasions 2010, 12, 1285-1294. [CrossRef]

3. Murphy, G.E.P.; Romanuk, T.N. A meta-analysis of declines in local species richness from human disturbances. Ecol. Evol. 2014, 4, 91-103. [CrossRef] [PubMed]

4. Goldstein, L.J.; Suding, K.N. Applying competition theory to invasion: Resource impacts indicate invasion mechanisms in California shrublands. Biol. Invasions 2014, 16, 191-203. [CrossRef]

5. Reinhart, K.O. The role of facilitative interactions in tree invasions. New Phytol. 2010, 187, 559-562. [CrossRef]

6. Peltzer, D.A.; Kurokawa, H.; Wardle, D.A. Soil fertility and disturbance interact to drive contrasting responses of co-occurring native and nonnative species. Ecology 2016, 97, 515-529. [CrossRef] 
7. Gavilán, R.G.; Sánchez-Mata, D.; Gaudencio, M.; Gutiérrez-Girón, A.; Vilches, B. Impact of the non-indigenous shrub species Spartium junceum (Fabaceae) on native vegetation in central Spain. J. Plant Ecol. 2016, 9, 195-202. [CrossRef]

8. Perry, L.G.; Galatowitsch, S.M.; Rosen, C.J. Competitive control of invasive vegetation: A native wetland sedge suppresses Phalaris arundinacea in carbon-enriched soil. J. Appl. Ecol. 2004, 41, 151-162. [CrossRef]

9. Canfield, D.E.; Glazer, A.N.; Falkowski, P.G. The Evolution and Future of Earth's Nitrogen Cycle. Science 2010, 330, 192-196. [CrossRef]

10. Vitousek, P.M.; Hattenschwiler, S.; Olander, L.; Allison, S. Nitrogen and nature. AMBIO 2002, 31, 97-101. [CrossRef]

11. Xu, X.; Bai, J.; Ouyang, H. Advances in Studies on Organic Nitrogen Uptake by Terrestrial Plants. J. Nat. Resour. 2011, 26, 715-724.

12. Kraiser, T.; Gras, D.E.; Gutierrez, A.G.; Gonzalez, B.; Gutierrez, R.A. A holistic view of nitrogen acquisition in plants. J. Exp. Bot. 2011, 62, 1455-1466. [CrossRef] [PubMed]

13. Xu, X.; Ouyang, H.; Kuzyakov, Y.; Richter, A.; Wanek, W. Significance of organic nitrogen acquisition for dominant plant species in an alpine meadow on the Tibet plateau, China. Plant Soil 2006, 285, 221-231. [CrossRef]

14. Mangla, S.; Sheley, R.L.; James, J.J.; Radosevich, S.R. Intra and interspecific competition among invasive and native species during early stages of plant growth. Plant Ecol. 2011, 212, 531-542. [CrossRef]

15. Miller, A.E.; Bowman, W.D.; Suding, K.N. Plant uptake of inorganic and organic nitrogen: Neighbor identity matters. Ecology 2007, 88, 1832-1840. [CrossRef]

16. Miller, A.E.; Bowman, W.D. Alpine plants show species-level differences in the uptake of organic and inorganic nitrogen. Plant Soil 2003, 250, 283-292. [CrossRef]

17. Yong, T.; Liu, X.; Yang, F.; Song, C.; Wang, X.; Liu, W.; Su, B.; Zhou, L.; Yang, W. Characteristics of Nitrogen Uptake, Use and Transfer in a Wheat-Maize-Soybean Relay Intercropping System. Plant Prod. Sci. 2015, 18, 388-397. [CrossRef]

18. Ashton, I.W.; Miller, A.E.; Bowman, W.D.; Suding, K.N. Nitrogen preferences and plant-soil feedbacks as influenced by neighbors in the alpine tundra. Oecologia 2008, 156, 625-636. [CrossRef]

19. Xiao, Y.B.; Li, L.; Zhang, F.S. Effect of root contact on interspecific competition and $\mathrm{N}$ transfer between wheat and fababean using direct and indirect N-15 techniques. Plant Soil 2004, 262, 45-54. [CrossRef]

20. Shen, H.; Dong, S.; Li, S.; Xiao, J.; Han, Y.; Yang, M.; Zhang, J.; Gao, X.; Xu, Y.; Li, Y.; et al. Effects of simulated $\mathrm{N}$ deposition on photosynthesis and productivity of key plants from different functional groups of alpine meadow on Qinghai-Tibetan plateau. Environ. Pollut. 2019, 251, 731-737. [CrossRef]

21. Shen, H.; Dong, S.; Li, S.; Xiao, J.; Han, Y.; Yang, M.; Zhang, J.; Gao, X.; Xu, Y.; Li, Y.; et al. Grazing enhances plant photosynthetic capacity by altering soil nitrogen in alpine grasslands on the Qinghai-Tibetan plateau. Agric. Ecosyst. Environ. 2019, 280, 161-168. [CrossRef]

22. Trinder, C.; Brooker, R.; Davidson, H.; Robinson, D. Dynamic trajectories of growth and nitrogen capture by competing plants. New Phytol. 2012, 193, 948-958. [CrossRef] [PubMed]

23. Corre-Hellou, G.; Fustec, J.; Crozat, Y. Interspecific competition for soil N and its interaction with N-2 fixation, leaf expansion and crop growth in pea-barley intercrops. Plant Soil 2006, 282, 195-208. [CrossRef]

24. Julien, M.H.; Skarratt, B.; Maywald, G.F. Potential geographical distribution of alligator weed and its biological control by Agasicles hygrophila. J. Aquat. Plant Manag. 1995, 33, 55-60.

25. Lowe, S.; Browne, M.; Boudjelas, S.; De Poorter, M. 100 of the World's Worst Invasive Alien Species: A Selection from the Global Invasive Species Database; Invasive Species Specialist Group: Auckland, New Zealand, 2000; Volume 12.

26. Jones, D.L.; Kielland, K. Soil amino acid turnover dominates the nitrogen flux in permafrost-dominated taiga forest soils. Soil Biol. Biochem. 2002, 34, 209-219. [CrossRef]

27. Pang, R.; Sun, Y.; Xu, X.; Song, M.; Ouyang, H. Effects of clipping and shading on ${ }^{15} \mathrm{NO}_{3}{ }^{-}$and ${ }^{15} \mathrm{NH}_{4}{ }^{+}$ recovery by plants in grazed and ungrazed temperate grasslands. Plant Soil 2018, 433, 339-352. [CrossRef]

28. Liu, M.; Qiao, N.; Zhang, Q.; Xu, X. Cropping regimes affect $\mathrm{NO}_{3}{ }^{-}$versus $\mathrm{NH}_{4}{ }^{+}$uptake by Zea mays and Glycine max. Plant Soil 2018, 426, 241-251. [CrossRef]

29. Zhou, Y.; Li, L.; Gao, J.; Ding, Y. Effects of interspecific competition on the growth of invasive and native species. Chin. J. Ecol. 2016. [CrossRef] 
30. Quan, W.M.; Han, J.D.; Shen, A.L.; Ping, X.Y.; Qian, P.L.; Li, C.J.; Shi, L.Y.; Chen, Y.Q. Uptake and distribution of N, P and heavy metals in three dominant salt marsh macrophytes from Yangtze River estuary, China. Mar. Environ. Res. 2007, 64, 21-37. [CrossRef]

31. Fickbohm, S.S.; Zhu, W.X. Exotic purple loosestrife invasion of native cattail freshwater wetlands: Effects on organic matter distribution and soil nitrogen cycling. Appl. Soil Ecol. 2006, 32, 123-131. [CrossRef]

32. Mozdzer, T.J.; Brisson, J.; Hazelton, E.L.G. Physiological ecology and functional traits of North American native and Eurasian introduced Phragmites australis lineages. AoB Plants 2013, 5. [CrossRef]

33. Leffler, A.J.; James, J.J.; Monaco, T.A. Temperature and functional traits influence differences in nitrogen uptake capacity between native and invasive grasses. Oecologia 2013, 171, 51-60. [CrossRef] [PubMed]

34. Matzek, V. Superior performance and nutrient-use efficiency of invasive plants over non-invasive congeners in a resource-limited environment. Biol. Invasions 2011, 13, 3005-3014. [CrossRef]

35. Qing, H.; Cai, Y.; Xiao, Y.; Yao, Y.; An, S. Nitrogen Uptake and Use Efficiency of Invasive Spartina alterniflora and Native Phragmites australis: Effect of Nitrogen Supply. Clean Soil Air Water 2015, 43, 305-311. [CrossRef]

36. Schimel, J.P.; Bennett, J. Nitrogen mineralization: Challenges of a changing paradigm. Ecology 2004, 85, 591-602. [CrossRef]

37. Zhang, Y.; Bai, S. Effects of nitrogen forms on nutrient uptake and growth of trees. Chin. J. Appl. Ecol. 2003, 14, 2044-2048.

38. Javaid, A. Arbuscular mycorrhizal mediated nutrition in plants. J. Plant Nutr. 2009, 32, 1595-1618. [CrossRef]

39. Andrews, M.; Raven, J.A.; Lea, P.J. Do plants need nitrate? The mechanisms by which nitrogen form affects plants. Ann. Appl. Biol. 2013, 163, 174-199. [CrossRef]

40. Hewins, D.B.; Hyatt, L.A. Flexible N uptake and assimilation mechanisms may assist biological invasion by Alliaria petiolata. Biol. Invasions 2010, 12, 2639-2647. [CrossRef]

41. Hawkes, C.V.; Wren, I.F.; Herman, D.J.; Firestone, M.K. Plant invasion alters nitrogen cycling by modifying the soil nitrifying community. Ecol. Lett. 2005, 8, 976-985. [CrossRef]

42. Reynolds, H.L.; Packer, A.; Bever, J.D.; Clay, K. Grassroots ecology: Plant-microbe-soil interactions as drivers of plant community structure and dynamics. Ecology 2003, 84, 2281-2291. [CrossRef]

43. Jackson, R.B.; Caldwell, M.M. Integrating Resource Heterogeneity and Plant Plasticity: Modelling Nitrate and Phosphate Uptake in a Patchy Soil Environment. J. Ecol. 1996, 84, 891-903. [CrossRef]

44. McKane, R.B.; Johnson, L.C.; Shaver, G.R.; Nadelhoffer, K.J.; Rastetter, E.B.; Fry, B.; Giblin, A.E.; Kielland, K.; Kwiatkowski, B.L.; Laundre, J.A.; et al. Resource-based niches provide a basis for plant species diversity and dominance in arctic tundra. Nature 2002, 415, 68-71. [CrossRef] [PubMed]

45. Kielland, K. Amino acid absorption by arctic plants: Implications for plant nutrition and nitrogen cycling. Ecology 1994, 75, 2373-2383. [CrossRef]

46. Chapin III, F.S.; Moilanen, L.; Kielland, K. Preferential use of organic nitrogen for growth by a non-mycorrhizal arctic sedge. Nature 1993, 361, 150. [CrossRef] 